\title{
An Exploration of Secondary Students' Mental States when Learning about Acids and Bases
}

\begin{abstract}
This study explored factors of students' mental states, including emotion, intention, internal mental representation and external mental representation, which can affect their learning perfor-
\end{abstract} mance. In evaluating students' mental states during the science learning process and the relationship between mental states and learning achievement, valid, reliable and scalable measures of students' mental states and learning achievement are needed. This paper presents the development of the Mental State Conceptual Learning Inventory (MSCLI) to identify students' mental states before and after learning about acids and bases. This instrument is time-efficient and convenient and can be administered to large student samples so that teachers and researchers can gain profound insights into their students' learning of acids and bases in science class. The results of this study indicate that students' mental states are highly correlated with their achievement. As a whole, low-achieving students tended to have negative emotions and low intentions, were not good at internal visualization and were unable to interpret graphics and draw pictures. In contrast, high-achieving students had positive emotions and intentions when learning life-related topics about acids and bases, and were good at internal visualization and drawing and interpreting graphics.

Keywords: Mental state, acids and bases, emotion, intention, conceptual change learning 


\section{Introduction}

For more than 30 years, research on scientific learning has had a growing focus on the issues about conceptual change (Author, 2007; Author, 2008; White \& Gunstone, 2008). Conceptual change is defined as the integration of preconceptions and the to-be-learned concepts in which learners have altered and accommodated the preconception to new conceptions in the process of understanding the desirable or intended knowledge (Author, 2003; Sinatra \& Pintrich, 2003). Teaching which focuses on conceptual change learning is beginning to have a positive impact on student science achievement (Ebenezer, Chacko, Kaya, Koya, \& Ebenezer, 2010). However, the fact that it is difficult for some students to transform their prior knowledge in science class cannot be ignored (Vosniadou, 2007). Science teachers and educators need to know those factors that influence students' science learning so that they can adjust their teaching to enhance students' learning achievements.

The difficulties of changing scientific conceptions mainly from the cognitive perspective of learning, e.g. measurable cognitive outcomes, have been explored in empirical research. There are, however, a group of researchers and science educators who point out that the emotion and intention domains clearly play a significant role in science learning (Alsop, 2005; Alsop \& Watts, 2003; Pintrich, Marx, \& Boyle, 1993; Author, 2004; Sinatra, \& Pintrich, 2003; Author, 2008; Zembylas, 2005). These authors argue that students' learning emotions and intentions can facilitate or hinder conceptual change. In particular, Duschl (2008) contends that science learning takes place in complex settings of cognitive, epistemic, and social practices in which the psychological component is rarely researched. 
Therefore, it is crucial to recognize the value and importance that this psychological component plays

in science learning.

In addition, Chi (1992) emphasizes that the ontological categorization of concepts can be used to

explicate the situation of conceptual change. She divided ontology into three primary categories:

matter, process and mental states. Investigations of the difficulty of conceptual change about onto-

logical categories of matter and process have shown that if the to-be-learned concepts and the prior knowledge are ontologically compatible, for instance, both are matter which can be contained, have weight, and occupy space (like trees and coal), then conceptual change is more easily completed (Chi, 1992; Chi, Slotta, \& de Leeuw, 1994; Author, 2003; Author, 2005). When the two concepts are ontologically distinct, learning becomes difficult. If students lack awareness of when a shift is necessary or lack an alternative category to shift into, the process of conceptual change also becomes difficult (Chi \& Roscoe, 2002). But, rarely do studies discuss conceptual change from the ontological category of mental states. Based on the importance of psychological conditions in science learning (Duschl, 2008), it is essential to explore students' mental states when they are learning science and examine how the mental states relate to students' learning achievement.

The need for exploring conceptual learning from a mental states perspective, and the lack of an existing measurement instrument led to the development of the Mental State Conceptual Learning Inventory (MSCLI), which can provide researchers and teachers with a more comprehensive understanding of science learning. Previous research on conceptual change learning of acid and base 
chemistry mainly used data collected from standard achievement tests and interviews (Artdej, Ratanaroutai, Coll, \& Thongpanchang, 2010; Ouertatani, Dumon, Trabelsi-Ayadi, \& Soudani, 2007;

McClary \& Talanquer, 2011). However, achievement tests and interviews arguably do not provide easy access for teachers to examine students' conceptual learning from a mental states perspective during science learning. Interviews can be time-consuming and require sophisticated interviewing skills to investigate the target area, while standard achievement tests only measure the knowledge that students have gained. Thus, the purpose of this study was to develop a Mental State Conceptual Learning Inventory (MSCLI) which is time-efficient and convenient and can be administered to large samples so that teachers and researchers can gain profound insights into the learning of conceptual change in science classes. The three aims of this study are to:

1. Explore the factors of mental states from the perspectives of conceptual learning.

2. Develop the MSCLI to investigate the mental states of secondary students while learning about acids and bases.

3. Verify the appropriateness of the MSCLI through investigating the relation between mental states and achievement as well as by interviews.

\section{Theoretical Framework of Mental States}

Mental states refer to the states caused by the interaction between students' psychological status and mental representations during science learning, and such states influence the conceptual learning of students. Mental states are based on Functionalism (Sehon, 1994), and they are the main fac- 
tors which cause an individual to possess various states resulting from interactions between humans and their environment. People often use mental states' predicates to demonstrate their reactions (for example, anxious, and eager), and describe their attitudes (for example, believe, need, hope) (Hanoch, 1997). When students enter the science classroom to start learning scientific concepts, they also have different mental states for the scientific concepts. These mental states may include emotions concerning scientific concepts, intentions to learn a scientific concept as well as holding mental representations of scientific concepts. These mental states will not only affect students' understanding of the scientific concepts but also influence the effectiveness of learning as students undergo conceptual change.

Perner (1991) specified that mental states were kinds of human internal energy which activate and produce the observed mental habits, thinking, and techniques. Attributes of mental states are identified by researchers as suspecting, experiencing pain, worrying, intending, demanding, agreeing, accepting, refusing, believing, liking, being interested, understanding, being joyful, thinking, concentrating, being stressed, being excited, being confident, being sure, holding values and applying tactics (Costa \& Kallick, 2000; Ondáš, Bevacqua, Juhár, \& Demeter, 2010; Purton, 1998; Sobol-Shikler, 2011). Very importantly, attributes of mental states are considered highly related to cognitive ability. Jaggar (1989) also argued that the cognitive domain is intrinsically correlated with the affective domain during the learning process. More recently, Zull (2011) has stated that emotion ids probably the most important factor for learning. Consequently, understanding students' mental 
states during learning of scientific concepts is an important starting point for teachers to intervene in student learning. Mental states can be used to explain, predict, and understand behavior, the internal state, and the situational condition as well as any relationships among the three (Leslie, 1994). So, while learning science, students' mental states can influence not only the learning motivation and attitudes but also the product of conceptual learning.

To explore conceptual learning from the viewpoint of mental states, the present study took the standpoint of Chi's (1997) theory in which the ontology was divided into three primary categories: matter, process and mental states. Mental states were further subcategorized into emotion and intention. Emotions have substantial influence on what happens in the science classroom and should receive more attention in science learning (Alsop, 2005; Zull, 2011). For instance, empirical studies related to student disaffection with science have centered on emotional patterns and its relationship to science learning (Zembylas, 2005), and a lack of interest and motivation is highly related to students' detachment from science learning (Osborne, Simon, \& Collins, 2003). Furthermore, an individual's emotion influences the achievement of a goal: experiencing happiness and sadness may motivate a person to approach the goal, while relaxation and anxiety may lessen the motivation and create a detachment from goal achievement (Linnenbrink \& Pintrich, 2002).

Intention is another influential factor of mental states in science learning. When intention is developed, a plan to successfully achieve the goal is formed and a belief of implementing the plan occurs (Feinfield, Lee, Flavell, Green, \& Flavell, 1999). Intentional processing is goal-oriented and 
under the learner's control, enabling conscious initiation and regulation of cognitive, meta-cognitive and motivational processes to bring out a change in knowledge (Sinatra \& Pintrich, 2003). Therefore, intention as well as emotion can facilitate or impede conceptual change (Sinatra, Southerland, McConaughy, \& Demastes, 2003). Relevant research showed that performance of students with low prior-knowledge would be affected by their intention while learning scientific concepts (Author, 2004).

In science learning, not only students' psychological state (for example, emotion and intention), but also students' mental representations of scientific concepts would affect conceptual change and are the ways that individuals establish and transform information (McKendree, Small, Stenning, \& Conlon, 2002). In addition to evaluation and memory, mental representations also have a motivational function (Paivio, 1986). The changes of mental representations are thought to affect motivation, and the response of the emotion is considered to correlate with the level of motivation, too. In other words, mental representations interact with the psychological state, and influence learning performance. To understand fully students' conceptual change from the viewpoint of mental states, it is also essential to examine the representation of cognitive structures and processes.

One major difficulty encountered by secondary students in science learning is that the attention of the majority of students is centered on what is observed such as a physical model rather than the underlying principles (Gilbert, 1991; Gilbert \& Boulter, 1998, 2000). To enhance learners' understanding of abstract, less comprehensible, and unobservable scientific concepts, a static model, anal- 
ogy, picture, graphic, idea, and concrete and abstract visual representations can be used (Gilbert, Reiner \& Nakhleh, 2008; Moreno, Ozogul, \& Reisslein, 2011; Author, 1994). However, when learning the concept of Plate Tectonics, Author (2004) found that high-achieving students were affected mainly by the changes in their internal mental representation of their mental image and analogy, the connection between the knowledge representations, having a skeptical attitude towards the target knowledge, and the means used to handle the uncertainty. Meanwhile, low-achieving students were not able to make connections across different representations. The finding of students not being able to connect or move across multiple representations was also observed by Kozma (2003) and by many of the authors in Gilbert and Treagust (2009)..

Author et al. (2003) showed that students' preconceptions have the top-down influence on interpreting the representations, and the pre-experience has an effect on the thinking and explication of the representations. For instance, Kendeou and van de Broek (2005) pointed out that after reading a science text, students with misconceptions produce different memory representations from those with correct scientific conceptions. Also, Jarodzka, Scheiter, Gerjetsand van Gog (2010) found that experts and novices notice diverse aspects of and extract distinct information from the representations. Using eye-tracker software, Authors (2011) also found that the participants with different prior-knowledge paid attention to different areas in reading scientific diagrams and the cognitive processing time also varied. Consequently, to optimise their classrom, teachers should take students' mental representations into account when designing the curriculum and assessing students' learning 
performance.

The Mental State Conceptual Learning Inventory (MSCLI) allows teachers to detect students' mental states more effectively so as to apply more appropriate strategies for science teaching. According to the above literature reviewed, the factors which influence students' mental states involve psychological states and mental representations of scientific concepts. Thus, Emotion, Intention, Internal Mental Representation and External Mental Representation are the four main aspects involved in the MSCLI. Based on these four aspects, survey items were developed and tested using factor analysis, interviews, and correlated with the achievement test on acids and bases.

\section{Methods}

To investigate students' mental states when learning about the conception of acids and bases, this study developed the Mental State Conceptual Learning Inventory (MSCLI). Moreover, an achievement test and interviews were conducted to certify the validity of MSCLI.

The concepts of acids and bases were chosen as the content of the questionnaire because they are the first abstract and sub-microscopic concepts with which secondary students come into contact in their science classes. de Vos and Pilot (2001) depicted that acid-base concepts contained material from six different layers or contexts. The learning process that students experience is that they are simply adding the concepts to previous layers without any restructuring of the acid-base content. Science conceptual learning at this level directly effects their abstract and sub-microscopic conceptual learning in the future (Artdej et al., 2010), so this is a valuable concept to be investigated. 


\section{Participants}

This study recruited four different groups of participants for four different tasks. All participants voluntarily participated in the study. The participants of the first task comprised six 9th-grade students who had completed the unit of acids and bases (two low-, two medium- and two high-achievers in the concept of acids and bases with one male and one female in each group), three science teachers who specialized in chemistry with seven years teaching experience, and three science educators. The participants of the second task consisted of 267 9th-grade students $($ males $=128$, females $=139)$ from seven classes who had completed the unit of acids and bases. The participants of the third task comprised 68 9th-grade students (33 males and 35 females) recruited from two classes in the same urban school in Taiwan who had not learned the concepts of acids and bases and to whom the Acids and Bases Achievement Test (ABAT) were administered both before and after instruction. The participants of group three were divided into three subgroups according to ABAT scores after learning: high-achieving group ( $\mathrm{N}=20)$, middle-achieving group $(\mathrm{N}=27)$, and low-achieving group $(\mathrm{N}=21)$. The participants of the fourth task were 12 students from the third group - four students (two males and two females) of each group - who volunteered to be interviewed in order to gain an in-depth insight of their learning processes. All students in this study were from the same urban school in Taiwan. In this school, all the classes were similar to the vast majority of secondary schools in Taiwan, being mixed-sex and having classes that contained students with different learning achievements. So, these students who participated in this study were representative of the secondary school students in Taiwan. 
Instrumentation

\section{Mental State Conceptual Learning Inventory (MSCLI)}

The present study adopted Author's (2003) mental state model which consists of four categories

- Emotion, Intention, Internal Mental Representation and External Mental Representation. Entities such as like, fear, suspect, pain, worry belong to the category of Emotion, while entities such as desire, want, pretend are classified as Intention. Entities such as imagine, look like, think, believe are grouped into Internal Mental Representations (IMR) while entities such as apply, express, interaction belong to External Mental Representations (EMR). The descriptive information of MSCLI is shown in Table 1. The questionnaire adopted a 5-point Likert Scale, in which 1= Almost Never, 2= Seldom, 3= Sometimes, 4= Often, and 5= Almost Always. Accordingly, negative items were reverse-scored. The Statistical Package for the Social Sciences (SPSS 17.0 ) was used to compute students' responses.

Table 1 Descriptive information in each MSCLI scale

\begin{tabular}{lll}
\hline Categories & \multicolumn{1}{c}{ Descriptions } & \multicolumn{1}{c}{ Examples } \\
\hline \multirow{2}{*}{ Emotions } & $\begin{array}{l}\text { Students' emotions towards science } \\
\text { classes and the unit of acids and bases. }\end{array}$ & $\begin{array}{l}\text { I like the unit of acids and bases. } \\
\text { the concepts of acids and bases. }\end{array}$ \\
& & \\
How intentions to gain affirmation & I want my instructor to know that I am work- \\
from others affect learning of physics & $\begin{array}{l}\text { ing hard on the unit of acids and bases. } \\
\text { I would work hard in science classes for the } \\
\text { and chemistry }\end{array}$ & praise from my parents. \\
& &
\end{tabular}


When talking about the dissolving process of Effects of image formation and transelectrolytes, my mental picture is that elecInternal mental forming of internal knowledge on representation learning during the process of learning.

trolytes dissociate in water.

I can use pictures and graphics to demonstrate the process of acid-base neutralization.

Using the concepts of acid-base neutralization The utilization of representation of and examples from daily life helps me solve

External mental acids and bases during problem solvrepresentation ing the problems of acids and bases.

A picture or graphic that comes with a problem about acid-base neutralization helps me solve the problem.

\section{Acids and Bases Achievement Test (ABAT).}

To further confirm that the MSCLI can address both cognitive and affective dimensions while learning, a test was used to investigate students' conceptual change by comparing pre- and post-instruction responses, and then criterion validity of MSCLI was confirmed. Subsequently, the Acids and Bases Achievement Test (ABAT) was designed by the authors as a result of not finding a suitable and dependable test in Taiwan.

The content of ABAT was based on students' commonly identified misconceptions of acids and bases (Artdej, et al., 2010; Furió-Más, Calatayud, Guisasola, \& Furió-Gómez, 2005; Lin \& Chiu, 2007; Nakhleh \& Krajcik, 1994; Ouertatani, et al., 2007), which were divided into macroscopic and submicroscopic concepts. The characteristics of acid and base materials and the judgment of neutralization are classified as the macroscopic concept, while the judgment of categories and the number of ions in solution, and the changes of the ion categories and numbers during reactions are considered as 
submicroscopic concepts, as illustrated in Table 2. The ABAT included eight multiple-choice questions and two drawing questions. Having completed the ABAT, the participants of the first group, including six students, three science teachers, and three science educators were invited to read through the test items in order to ascertain both face and content validities.

The standardization of scoring students' drawings was conducted by three science teachers before the formal scoring. After scoring students' responses, triangulation was then conducted to assure students' conceptual level. The reliability coefficient (KR-20) of eight multiple-choice questions was 0.76, and Cronbach's $\alpha$ of two drawing questions was .61. The test's reliability can be affected by the number of items and the level of heterogeneity of the content. The number of items tested in the achievement test was rather small, so the result of internal consistency gained was considered acceptable (Kubiszyn \& Borich, 1996).

Table 2 The concepts in the items of ABAT and the references of the concepts

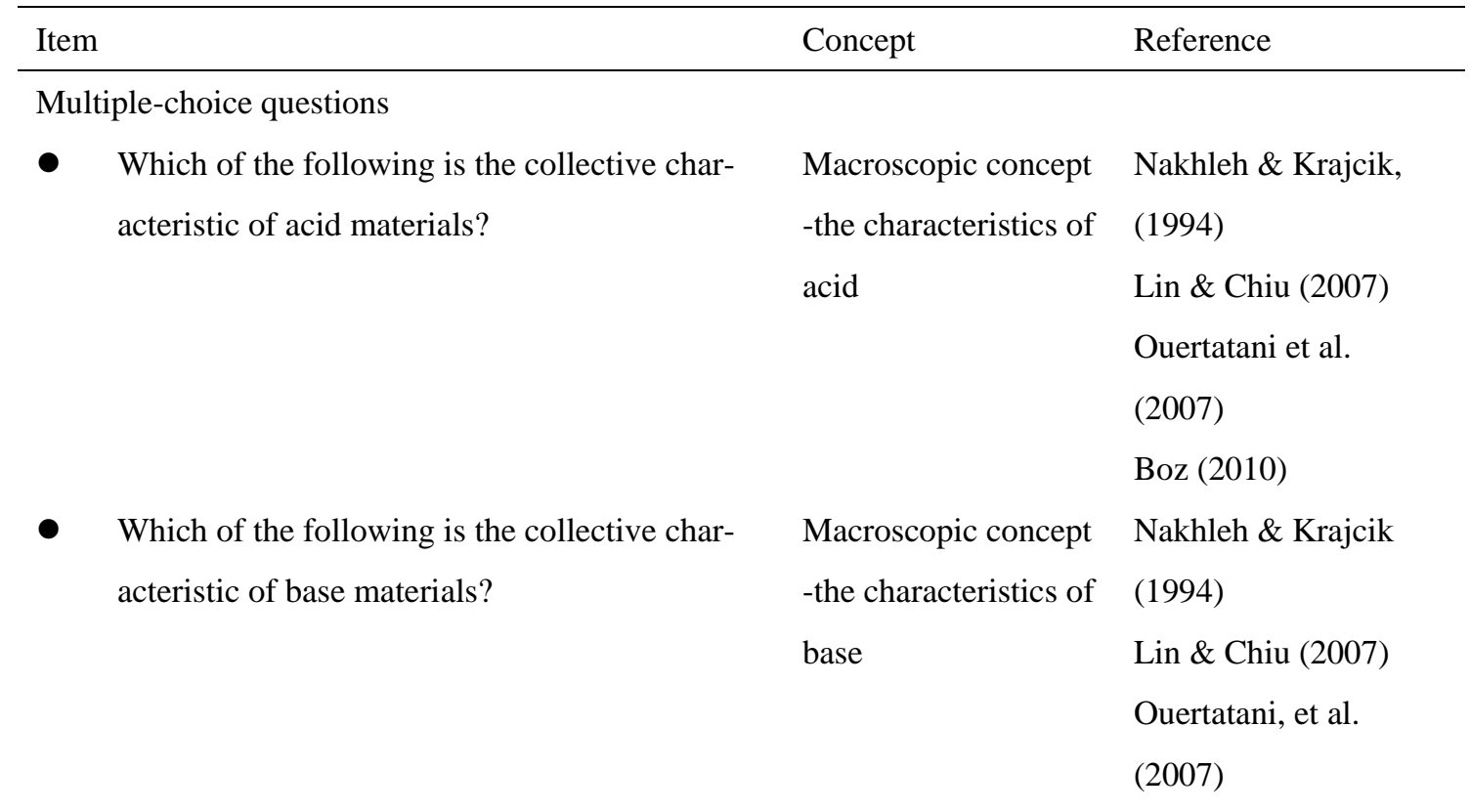


Boz (2010)

- Which of the following are not base materials?

Which of the following are not base materials?

Macroscopic concept -the identification of base materials

Nakhleh \& Krajcik (1994)

Lin \& Chiu (2007)

Ouertatani et al.

Boz (2010)

Macroscopic concept

-the judgments of

chemical reactions

about neutralization

Lin \& Chiu (2007)

Ouertatani et al.

(2007)

Boz (2010)

Microscopic concept

Lin \& Chiu (2007) -the judgments of the ion numbers hydrogen ion is counted to the mole of sulfate ion in this sulfuric acid aqueous?

- The following equation is about the ionization of calcium hydroxide aqueous:

$\mathrm{Ca}(\mathrm{OH})_{2} \rightarrow \mathrm{Ca}^{2+}+2 \mathrm{OH}^{-}$

What is the proportion of the numbers of $\mathrm{Ca}^{2+}$

to $\mathrm{OH}^{-}$in $1 \mathrm{M}, 10$ liters calcium hydroxide aqueous?

- What changes of the concentrations of $\left[\mathrm{H}^{+}\right]$and $\left[\mathrm{OH}^{-}\right]$in water when dissolved $1 \mathrm{~g}$ sodium hydroxide in 1 liters of water?

- Dissolve sodium hydroxide $(\mathrm{NaOH})$ in water, which statements of the following are correct?
Microscopic concept -the judgments of the ion numbers
Microscopic concept -the changes of the ion numbers

Microscopic concept -the changes of the ion numbers

Drawing questions

- Add quantitative chlorine calcium $\left(\mathrm{CaCl}_{2}\right)$ in the beaker of the following equipment. Try to draw the ionization and distribution situation.
Microscopic concept Lin \& Chiu (2007) -the changes of the Furió-Más, et al. ion numbers

(2005)
Furió-Más, et al.

(2005)

Furió-Más, et al. (2005) 


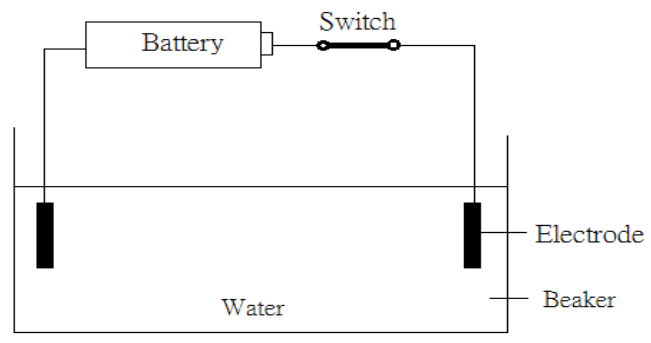

- Dilute $1 \mathrm{M} 10 \mathrm{~mL}$ sodium hydroxide aqueous into $100 \mathrm{~mL}$, and titrate by $0.5 \mathrm{M}$ diluted hydrochloric acid, then:

$\diamond \quad$ What situation do you think about the existence Microscopic concept Furió-Más, et al. of molecules and ions in beaker before titrat- $\quad$-the ion categories (2005) ing? and numbers

$\diamond \quad$ What situation about the existence of mole- $\quad$ Microscopic concept $\quad$ Furió-Más et al. cules and ions in beaker when adding $5 \mathrm{~mL}$ di- $\quad$-the ion categories luted hydrochloric acid in? and the changes of Ouertatani et al. ion numbers

$\diamond \quad$ What situation about the existence of moleMicroscopic concept Furió-Más, et al. cules and ions in beaker when the titration -the ion categories reaches to the end point? and the changes of ion numbers

$\diamond \quad$ Try to assess the consumed diluted hydrochloMicroscopic concept

Lin \& Chiu (2007) ric acid after titrating. -the proportion calFurió-Más, et al. culation of neutrali(2005) zation Boz (2010)

\section{Results}

\section{MSCLI Development and Validation}

Within the four main categories of mental states - Emotion, Intention, Internal Mental Representation and External Mental Representation - a total number of 102 items were developed.

Having generated the preliminary items of the questionnaire, the participants in the first group were invited to establish the validity of each item's content. Three science teachers and three science educators were invited to read the 102 items of the questionnaire in order to assure that all the items 
developed represented each category of mental states. The questionnaire was examined in terms of three aspects so as to ensure content validity: the suitability of each item in each mental state category, the inclusion of four mental state categories in the questionnaire, and the ratio of various types of items within each category. In addition, six students were invited to read these 102 items for a comprehensibility check in order to ensure face validity. Any incomprehensible word was modified based on students' feedback. Then the questionnaires were distributed to the second group of participants. According to the participants' responses, item analysis, including descriptive statistics, a homogeneity test, and extreme group test, were carried out. Items with high missing rate, factor loading smaller than .3, low item-total correlation, and insignificant discrimination, were excluded (Glynn, Taasoobshirazi, \& Brickman, 2009).

Following that, exploratory factor analysis was conducted with the remaining items to identify the subscales of MSCLI. The purpose of conducting factor analysis was to test the reliability and validity of the scales. According to the results of KMO and Bartlett's Test, samples selected in this study were appropriate for conducting factor analysis. Next, the principal components analysis and the rotation method of Varimax with Kaiser Normalization were applied to find optimal ways for combining variables into a small number of subsets.

The results showed that the items developed could be grouped into four main factors. With regards to the equivalent number of items in each category, the number of items was reduced to ten each, totaling 40 items. Factor analysis was then repeated with these 40 items and the results gained 
are presented in Table 3. The mean scores, standard deviations, internal consistency, and discriminant validity for each scale of the MSCLI are shown in Table 4. The results reached the satisfactory level.

Table 3 Result of exploratory factor analysis

\begin{tabular}{|c|c|c|c|c|}
\hline \multirow{2}{*}{ Items } & \multicolumn{4}{|c|}{ Rotated Factors Pattern } \\
\hline & Emotions & Intentions & $\begin{array}{l}\text { Internal mental } \\
\text { representation }\end{array}$ & $\begin{array}{l}\text { External mental rep- } \\
\text { resentation }\end{array}$ \\
\hline 1 & .523 & & & \\
\hline 2 & .554 & & & \\
\hline 3 & .563 & & & \\
\hline 4 & .473 & & & \\
\hline 5 & .608 & & & \\
\hline 6 & .836 & & & \\
\hline 7 & .693 & & & \\
\hline 8 & .648 & & & \\
\hline 9 & .799 & & & \\
\hline 10 & .545 & & & \\
\hline 11 & & .555 & & \\
\hline 12 & & .747 & & \\
\hline 13 & & .811 & & \\
\hline 14 & & .795 & & \\
\hline 15 & & .807 & & \\
\hline 16 & & .507 & & \\
\hline 17 & & .658 & & \\
\hline 18 & & .439 & & \\
\hline 19 & & .403 & & \\
\hline 20 & & .414 & & \\
\hline 21 & & & .691 & \\
\hline 22 & & & .515 & \\
\hline 23 & & & .680 & \\
\hline 24 & & & .624 & \\
\hline 25 & & & .652 & \\
\hline 26 & & & .450 & \\
\hline 27 & & & .714 & \\
\hline
\end{tabular}


Table 4 Mean scores $(M)$, standard deviations(S.D.), internal consistency (Cronbach's $\alpha$ ), and discriminant validity (mean correlation with other scales) on MSCLI $(\mathrm{n}=267)$

\begin{tabular}{lccccc}
\hline Scale & Item & $M$ & S.D. & Cronbach's $\alpha$ & $\begin{array}{r}\text { Mean Correlation } \\
\text { with Other Scales }\end{array}$ \\
\hline Emotions & 10 & 3.36 & 0.74 & 0.88 & .39 \\
$\begin{array}{l}\text { Intentions } \\
\text { Internal mental }\end{array}$ & 10 & 2.88 & 0.72 & 0.79 & .30 \\
$\begin{array}{l}\text { representation } \\
\text { External mental }\end{array}$ & 10 & 2.66 & 0.62 & 0.71 & .48 \\
representation & 10 & 3.87 & 0.65 & 0.70 & .40 \\
\hline
\end{tabular}

\section{Correlation between MSCLI and ABAT}

Pearson's correlation coefficient was applied to determine the criterion validity of MSCLI, using scores from the Acids and Bases test as a criterion. To validate the level of correlation between MSCLI and ABAT, these two instruments were administered to the participants of group three (68 students) 
both before and after instruction of the acids and bases topic. The results indicated that the MSCLI is highly correlated with the ABAT. Before learning, the Pearson correlation coefficient of the MSCLI and the ABAT was .42 $(p<.001)$, while the Pearson correlation coefficient was .39 $(p<.01)$ after learning. Therefore, the results showed that MSCLI and ABAT were moderately correlated; that is, students' mental state and the concept learning were interrelated. Most essentially, MSCLI contained the emotion and intention domains which were not included in ABAT. This, arguably, helps teachers develop a more comprehensive and informed understanding of students' learning conditions.

Analysis of Variance

The participants of group three were divided into three subgroups according to ABAT after learning: high-achieving group $(\mathrm{N}=20)$, middle-achieving group $(\mathrm{N}=27)$, and low-achieving group $(\mathrm{N}=21)$. Descriptive analysis of the individual factors of ABAT and MSCLI for these three groups before and after learning are presented in Table 5. The results of analysis of variance (ANOVA) also showed that there is a statistically significant difference among the three groups in Emotion before learning (see Table 6). After learning, three categories of mental states - Emotion, Internal Mental Representation External Mental Representation - also demonstrated statistically significant differences among these three groups indicating that the scores which the students gained on the MSCLI categories and their achievement of conceptual learning about acids and bases also had a high correlation. The results of post-hoc comparisons showed the students who had higher achievements on the ABAT had higher scores on the MSCLI. 
Therefore, science teachers can use the MSCLI instead of the achievement test to assess students' learning states before and after conceptual learning. In this way, science teachers can better appreciate students' psychological states and mental representations of the scientific concepts.

Table 5 Descriptive analysis \& $F$-test value of MSCLI and ABAT before- and after-learning

\begin{tabular}{|c|c|c|c|c|c|}
\hline \multirow{3}{*}{ Group } & \multirow{3}{*}{$\mathrm{N}$} & \multicolumn{2}{|c|}{ Before-learning } & \multicolumn{2}{|c|}{ After-learning } \\
\hline & & ABAT & MSCLI & ABAT & MSCLI \\
\hline & & $M(S D)$ & $M(S D)$ & $M(S D)$ & $M(S D)$ \\
\hline High-achieving & 20 & $63.0(12.4)$ & $113.7(15.1)$ & $79.1(8.5)$ & $131.8(18.8)$ \\
\hline Middle-achieving & 27 & $49.7(16.5)$ & $112.2(20.3)$ & $57.6(6.6)$ & $119.0(14.0)$ \\
\hline Low-achieving & 21 & $34.7(18.6)$ & $102.9(16.0)$ & $31.6(8.6)$ & $112.7(13.5)$ \\
\hline$F$ & & $15.8 * * *$ & 2.38 & $189.2 * * *$ & $6.39 *$ \\
\hline
\end{tabular}

$* p<.05 ; * * * p<.001$

Table 6 Descriptive analysis of each of factors of MSCLI before and after learning

\begin{tabular}{|c|c|c|c|c|c|c|c|c|}
\hline & \multicolumn{4}{|c|}{ Before- learning } & \multicolumn{4}{|c|}{ After-learning } \\
\hline & Emotions & Intentions & IMR & EMR & Emotions & Intentions & IMR & EMR \\
\hline High- & 35.7 & 20.7 & 25.1 & 32.3 & 35.1 & 28.9 & 29.4 & 38.5 \\
\hline achieving & $(6.0)$ & $(4.4)$ & $(5.4)$ & $(5.7)$ & $(7.5)$ & $(4.9)$ & $(5.0)$ & (6.6) \\
\hline Middle- & 33.7 & 21.4 & 24.4 & 32.7 & 30.9 & 26.2 & 25.2 & 36.6 \\
\hline achieving & $(7.9)$ & $(6.4)$ & $(6.7)$ & $(6.9)$ & $(9.4)$ & $(7.0)$ & $(6.2)$ & (6.0) \\
\hline Low- & 28.7 & 22.9 & 22.2 & 29.1 & 28.2 & 27.7 & 24.0 & 32.8 \\
\hline achieving & $(7.5)$ & (6.6) & $(5.6)$ & (6.6) & $(5.1)$ & (5.7) & 4.8) & (7.2) \\
\hline
\end{tabular}




\begin{tabular}{lllllllll}
$F$ & $5.21 * *$ & .70 & 1.29 & 1.98 & $4.05^{*}$ & 1.15 & $5.47 * *$ & $4.07 *$ \\
\hline
\end{tabular}

$* p<.05 ; * * p<.01 ; * * * p<.001$

Analysis of Interviews

In the present study, one-to-one semi-structured interviews were conducted with the fourth group of 12 students after learning the acid-base concepts in order to gain more in-depth understanding of the relationship between the students' mental states and the learning of acid-base concepts. The voluntary participants of each achieving group are named LS (Low-achieving group, numbered LS01 LS04), MS (Middle-achieving group, numbered MS01 MS04), and HS (High-achieving group, numbered HS01 HS04). Interview questions used were the questions listed in the questionnaire, including four dimensions (Emotions, Intentions, IMR, and EMR). Each individual interview lasted approximately 90 minutes. With the interview data, the mental state of students with different learning achievements was classified and summarized by the researchers. This summary further ascertained the impact of emotion, intention, internal mental representation and external mental representation on concept learning of acids and bases. Also, it facilitated the establishment of the construct validity of MSCLI. The results are as follows.

The Influence of Emotion on Conceptual Learning of Acids and Bases

Three of LS $(75 \%)$ stated that they worried most about the numerical calculations but not the content when learning chemistry as claimed by LS01 "I don't like chemistry when encountering numerical calculations." Two of LS mentioned that continuously thinking critically made them dislike 
science. However, both emotion and the scientific concepts influenced MS least in their learning, though punishment and achievement influenced them greatly, as stated by MS03 "I like chemistry whenever I feel a sense of achievement in learning it." For MS, punishment could cause stress though it enhanced students' learning motivation as well. When members of this group had improved their achievement, their emotion in learning strengthened. Finally, each of the HS (100\%) considered that learning content could influence their emotion in learning, especially they showed high interest in topics related to daily life as HS02 stated "I prefer studying theories which are highly related to daily life. So, after attending the class, I can understand more daily-life chemistry...I can check out the components of household cleaners at home."

The Influence of Intention on Conceptual Learning of Acids and Bases.

The learning intentions of LS were influenced both by themselves and their peers. The students stated that their parents did not expect them to achieve highly in science as stated by LS02 “I'm quite passive in terms of learning because my family never forces me to study hard." Also, they did not wish the teacher to understand their learning situation because they worry that the teacher might be too demanding.

MS thought that their parents' encouragement and expectation, as well as teachers and peers' attitudes, greatly influenced their learning intentions. As MS03 said "Both of my parents' requirement and encouragement influence my learning a lot.... For me it is very important to please my parents. As long as they are happy, I am happy." When confronting a problem, they preferred to ask their 
peers, rather than their teachers because they either felt embarrassed or considered the answer given by the teacher was more complicated than the one from their peers. However, they cared more about the comments made by their teachers and relatives than their peers.

HS considered that learning science was mainly for themselves to better understand their daily life and be able to enroll in a better high school in the future as claimed by HS02 "That I study hard is mainly for my own sake...I feel good, when I get good scores...besides, I also learn a lot at school." The parents of HS always told them that studying is for their own sakes, and HS paid less attention to peers' and teachers' opinions. They hoped that their parents could encourage them more verbally. When encountering problems in the learning process, they would check out their textbooks, discuss with their peers, and then ask their teachers. They did not show resistance to asking questions of their teachers.

The Influence of Internal Mental Representations on The Conceptual Learning of Acids and Bases.

All of LS related the concepts of acids and bases with substances with particular attributes such as being toxic, corrosive, or a particular $\mathrm{pH}$ level. They rarely connected the acid-base concepts with images, as LS04 claimed that "when the concept of acids and bases is mentioned, I think about only two words, acids and bases...I've never seen them. Molecules and ions are so small that we cannot see them in daily life." When they were required to imagine the motion of particles in liquids, three out of four (75\%) said that the particles were continuously 'moving irregularly', but they did not un- 
derstand why it happened. LS were never skeptical about what the teachers taught them unless their peers mentioned it.

MS deemed the particles in liquids would become motionless after the liquid had been poured into a container for some time. Each of them imagined that particles could be distinguished by their size and color and considered that the particles were round. MS never challenged what the teacher taught but when the teachers' instruction conflicted with their previous knowledge, they would discuss this with their peers.

The concepts about fundamental particles of HS were close to that of scientists: they understood, to a certain extent, the motion and appearance of the particles. Their image of the process of particles dissolving was able to be pictured and they also had greater imagination towards the submicrocosmic as reported by HS01 that "when talking about the concept of acids and bases, I imagine that the ions rumble...Molecules dissociate like bubbles that keep flowing out or like popcorn popping out...in a glass of water, Hydrogen ions and Hydroxide ions keep bumping into each other." In line with LS and MS, HS rarely asked questions of their teachers and of the content in the textbooks. Only when other students mentioned it or the knowledge delivered by the teacher or textbook conflicted with their preconception, would they ask questions of the teacher.

The Influence of External Mental Representations on The Conceptual Learning of Acids and Bases.

Each of the LS considered pictures could help them think when taking tests but they were not 
confident in understanding and drawing pictures. As LS03 stated that "It is difficult for me to understand pictures...but pictures can help me to think about something." MS believed that they could draw simple pictures only and it took some time for them to understand a picture which they had never seen before. MS01 said that "I can draw simple diagrams, but it will take a long time to draw difficult diagrams... when I encounter a new diagram, I need to spend a long time in comprehending it." This group of students also could not analyze and explicate the pictures or graphs comprehensively.

In contrast, HS were confident in drawing graphs and pictures and highlighted the main points. They could express their concepts of acids and bases with pictures and considered themselves to be good at understanding pictures. As HS03 said, "I can understand abstract diagrams and it is easier for me to read the diagram rather than the text $\cdots$ it is also easier to imagine when a question provides diagrams."

The above results revealed that mental states affected conceptual learning. This finding ascertains more exactly the necessity for the development of the MSCLI to assist teachers in understanding students' mental state before and after instruction.

\section{Discussion}

Based on the development and assessment of MSCLI, the results of ABAT, and the interview data gained from the secondary students, the functions of MSCLI provide the following outcomes.

An Understanding of Students' Emotion and Intention on Scientific Conceptual Learning of Acids 
and Bases

The results of the MSCLI assessment indicated that low-achieving students had more negative emotion (such as anxiety) in conceptual learning of acids and bases, while the high-achieving students have relatively good emotions in learning the concepts of acids and bases as related to daily life. Such information informs science teachers that topics related to life experiences are considered as one factor which motivates students' learning emotions towards the to-be-learned concept. The MSCLI and the ABAT at this level reveal the relationships between students' learning emotion and their achievement. However, factors which can enhance low-achieving students' learning emotions need to be further explored.

Results from the interviews indicate that students whose intentions are built on parental expectations might have higher learning achievements, although there is no significant correlation between the data from MSCLI and ABAT. Students who consider studying as their way to a better understanding of daily life and a promising future are productive learners who have a higher learning achievement. Thus, teachers may try to express their expectations and requirements to students as a way to motivate them. Furthermore, teachers can emphasize the importance of science knowledge in their daily lives and their future careers. With the expectations and requirements from teachers, students might figure out the importance of science learning which stimulates their learning intentions. Nevertheless, factors which motivate low achieving students require further investigation. An Understanding of Students' Internal and External Mental Representations on Scientific Conceptu- 
al Learning of Acids and Bases

The MSCLI enables teachers to understand students' submicroscopic concepts about acids and bases before instruction. A student's learning achievement is related to his/her internal interpretation of submicroscopic particles. Those who are capable of visualizing the particle's dissolving process and the intangible submicroscopic particle universe tend to have better learning achievements. On the contrary, those who are not good at internal visualization tend to have inferior learning achievements. Therefore, enhancing students' ability to interpret submicroscopic particles is what teachers should strive toward. This can be done, for example, by presenting pictures and static models or using analogies (Moreno, Ozogul, \& Reisslein, 2011; Author, 1994).

The administration of the MSCLI also enables teachers to have a better understanding of students' external mental representations. The results indicated that low-achieving students are not confident in their abilities to understand graphics and drawings. This finding of the current study is consistent with those of Sheppard (2006) and Artdej et al., (2010) who found that low-achieving students were unable to describe accurately acid-base concepts, while high-achieving students are confident in their understanding of graphics and their ability to drawings. The high-achieving students can express their thoughts about submicroscopic concepts. These results inform the teacher that they can work on enhancing low-achieving students' confidence in their abilities to understand graphics and make drawings as well as provide them with more opportunities to express their thoughts about the submicroscopic concepts. 


\section{Conclusions and Implications}

The present study has explored students' mental states during conceptual learning of acids and bases (aim 1). Exploring conceptual learning from the view of mental states can provide a comprehensive understanding about students' learning. The MSCLI developed for this study is time efficient, and allows teachers and researchers to collect the data from a large sample in a short time to gain deeper insights into students' mental states during the learning process.

Specifically, this study developed the MSCLI and ABAT to examine secondary students' mental states when learning about acids and bases (aim 2). The results clearly indicate that students' mental states are highly correlated with their achievements (aim 3). As a whole, low-achieving students tended to have negative emotions and low intentions, were not good at internal visualization and were unable to interpret graphics and draw pictures. In contrast, high achieving students were more foresighted. The intention of their study of acids and bases had gone beyond the learning of chemistry itself. They extended the intention of the learning to have a better understanding about life and a promising future. Generally speaking, they had higher emotion and intention when learning life related topics, and were good at internal visualization and drawing and interpreting graphics.

This study does not only evaluate students' mental states during conceptual learning and yield insightful information of why some students can achieve better conceptual change and others cannot from a psychological perspective, but also provides chemistry teachers and researchers with information on students' mental states prior to instruction. The application of the tests might also be used 
to enhance students' learning because teachers can identify and incorporate students' conceptions and representations into their teaching strategies.

According to socio-constructivist view of learning, students' psychological status cannot and should not be overlooked. Vygotskian theory accentuates the mutual interaction between the emotional and the cognitive (Nelmes, 2003). Thus, the identification of students' mental states is an essential step to increase teachers' awareness of learners' pre-existing concepts. It is important that teachers explore their students' mental states before instruction in order to facilitate students' learning conditions. It can be argued that the MSCLI is of practical value and can be very useful for teachers. 


\section{References}

Alsop, S. (2005). Beyond Cartesian dualisms-encountering affect in the teaching and learning of science. Dordrecht, Netherlands: Springer.

Alsop, S., \& Watts, M. (2003). Science education and affect. International journal of Science Education, 25, 1043-1047.

Artdej, R., Ratanaroutai, T., Coll, R. K., \& Thongpanchang, T. (2010). Thai Grade 11 students' alternative conceptions for acid-base chemistry. Research in Science \& Technological Education, $28(2), 167-183$

Author (2000). International Journal of Science Education.

Author (2003). International Journal of Science Education..

Author (2003). the Third International Conference on Science, Mathematics and Technology Education, South Africa.

Author (2003). International Journal of Science Education.

Author (2004). Chinese Journal of Science Education.

Author (2005). International Journal of Science \& Mathematics Education.

Author (2007). International Journal of Science Education.

Author (2008). International handbook of research on conceptual change.

Author (2008). Cultural Studies of Science Education.

Author (2011). Bulletin of Educational Psychology . 
Chi, M. T. H. (1992). Conceptual change within and across ontological categories: Examples from learning and discovery in science. In R. N. Giere (Ed.), Cognitive models of science (pp. 129-186). Minneapolis: University of Minnesota.

Chi, M. T. H. (1997). Creativity: Shifting across ontological categories flexibly. In T. B. Ward, S. M. Smith, \& J. Vaid (Eds.), Creative thought: AN investigation of conceptual structures and processe (pp. 209-234). Washington, DC: American Psychological Association.

Chi, M. T. H., \& Roscoe, R. (2002). The processes and challenges of conceptual change. In M. Limon \& L. Mason (Eds.), Reconsidering conceptual change: Issues in theory and practice (pp. 3-27). Dordrecht: Kluwer.

Chi, M. T. H., Slotta, J. D., \& de Leeuw, N. (1994). From things to processes: A theory of conceptual change for learning science concepts. Learning and Instruction, 4, $27-43$.

Costa, A. L., \& Kallick, B. (2000). Discovering and exploring habits of mind. Alexandria, VA: Association for Supervision and Curriculum Development.

de Vos, W. \& Pilot, A. (2001), Acids and bases in layers: the stratal structure of an ancient topic, Journal of Chemical Education, 78, 494-499.

Duschl, R. (2008). Science education in three- part Harmony: Balancing conceptual, epistemic, and social learning goals. Review of Research in Education, 32, 268-292.

Ebenezer, J., Chacko, S., Kaya, O. N., Koya, S. K., \& Ebenezer, D. L. (2010). Effects of common knowledge construction model sequence of lessons on science achievement and relational 
conceptual change. Journal of Research in Science Teaching, 47(1), 25-46.

Feinfield, K. A., Lee, P. P., Flavell, E. R., Green, F. L., \& Flavell, J. H. (1999). Young children's understanding of intention. Cognitive Development, 14, 463-468.

Furió-Más, C., Calatayud, M. L., Guisasola, J., \& Furió-Gómez, C. (2005). How are the concepts and theories of acid-base reactions presented? Chemistry in textbooks and as presented by teachers. International Journal of Science Education, 27(11), 1337-1358.

Gilbert, S. W. (1991). Model building and definition of science. Journal of Research in Science Teaching, 28(1), 73-79.

Gilbert, J. K., \& Boulter, C. J. (1998). Learning science though models and modeling. In K. Tobin \& B. Frazer (Eds.), International handbook of science education (pp. 53-66). Dordrecht, the Netherlands: Kluwer.

Gilbert, J. K., \& Boulter, C. J. (2000). Developing models in science education. Dordrecht, the Netherlands: Kluwer.

Gilbert, J. K., Reiner, M. \& Nakhleh, M. (Eds.). (2008). Visualization: Theory and practice in science education.Springer

Gilbert, J. K. \& Treagust, D. F. (Eds.).(2009). Multiple representations in chemical education. Springer

Glynn, S. M., Taasoobshirazi, G., Brickman, P. (2009). Science Motivation Questionnaire: Construct validation with nonscience majors. Journal of Research in Science Teaching, 46(2), 127-146. 
Hanoch, B. Y. (1997). Against characterizing mental states as propositional attitudes, Philosophical Quarterly, 47(186), 84-89.

Jaggar, R. (1989). Love and knowledge: emotion in feminist epistemology. In A. Garry \& M. Pearsall (Eds.), Women, knowledge, reality (p.129-155). Boston: Unwin Hyman.

Jarodzka, H., Scheiter, K., Gerjets, P., \& van Gog, T. (2010). In the eyes of the beholder: How experts and novices interpret dynamic stimuli. Learning and Instruction, 20(2), 146-154.

Kendeou, P. \& van de Broek P. (2005). The effects of readers' misconceptions on comprehension of scientific text. Journal of Educational Psychology, 97(2), 235-245.

Kozma, R. (2003). The material features of multiple representations and their cognitive and social affordances for science understanding. Learning and Instruction, 13, 205-226.

Kubiszyn, T., \& Borich, G. (1996). Educational testing and measurement. 5th ed. New York: Harper Collins.

Lin, J. W., \& Chiu, M. H. (2007). Exploring the characteristics and diverse sources of students' mental models of acids and bases. International Journal of Science Education, 29(6), 771-803.

Linnenbrink, E. A., \& Pintrich, P. R. (2002). Motivation as an enabler for academic success. School Psychology Review, 31, 313-327.

McClary, L., \& V. Talanquer, V. (2011). College students' mental models of acids and acid strength. Journal of Research in Science Teaching, 48(4), 396-413.

McKendree, J., Small, C., Stenning, K., \& Conlon, T. (2002). The role of representation in teaching 
and learning critical thinking. Educational Review, 54(1), 57-67.

Moreno, R., Ozogul, G., \& Reisslein, M. (2011). Teaching with concrete and abstract visual representations: effects on students' problem solving, problem representations, and learning perceptions. Journal of Educational Psychology, 103(1), 32-47.

Nakhleh, M. B., \& Krajcik, J. S. (1994). Influence on levels of information as presented by different technologies on students' understanding of acid, base, and $\mathrm{pH}$ concepts. Journal of Research in Science Teaching, 31(10), 1077-1096.

Nelmes, P. (2003). Developing a conceptual framework for the role of the emotions in the language of teaching and learning. Paper presented at the Conference of the European Society for Research in Mathematics Education, Bellaria, Italy, February 28-March 3, 2003.

Ondáš, S., Bevacqua, E., Juhár, J., \& Demeter, P. (2010). Towards influencing of the conversational agent mental state in the task of active listening. Lecture Notes in Computer Science, 5967, 113-121.

Osborne, J., Simon, S., \& Collins, S. (2003). Attitudes towards science: a review of the literature and its implications. International Journal of Research in Science Education, 25, 1049-1079.

Ouertatani, L., Dumon, A., Trabelsi-Ayadi, M., \& Soudani, M. L. (2007). Acids and bases: The appropriation of the Arrhenius model by Tunisian grade 10 students. International Journal of Science and Mathematics Education, 5, 483-506.

Paivio, A. (1986). Mental representation : A Dual Coding Approach. New York Oxford University 
Press.

Perner, J. (1991). Understanding representational mind. Cambridge, MA: MIT Press.

Pintrich, P. R., Marx, R. W., \& Boyle, R. A. (1993). Beyond cold conceptual change: The role of motivational beliefs and classroom contextual factors in the process of conceptual change. $R e$ view of Educational Research, 63(2), 167-199.

Purton, A. J. (1998). Mental state attribution. Halifax, Nova Scotia: Dalhousie University.

Sehon, S. R. (1994). Teleology and the nature of mental states. American Philosophical Quarterly, $31(1), 63-72$.

Sheppard, K. (2006).High school students' understanding of titrations and related acid-base phenomena. Chemistry Education Research and Practice, 7(1), 32-45.

Sinatra, G. M., \& Pintrich, P. R. (2003). Intentional Conceptual Change. Mahwah, NJ: L. Erlbaum.

Sinatra, G. M., Southerland, S. A., McConaughy, F., \& Demastes, J. (2003). Intentions and beliefs in students' understanding and acceptance of biological evolution. Journal of research in science teaching, 40, 510-528.

Sobol-Shikler, T. (2011). Automatic inference of complex affective states. Computer Speech and Language, 25, 46-52.

Vosniadou, S. (2007). Conceptual change and education. Human Development, 50(1), 47-54.

White, R., \& Gunstone, R. (2008). The conceptual change approach and the teaching of science. In S. Vosniadou (Ed.), Handbook of research on conceptual change (pp. 619-628). Mahwah, NJ: L. 


\section{Erlbaum.}

Zembylas, M. (2005). Three perspectives on linking the cognitive and the emotional in science learning: conceptual change, socio-constructivism and poststructuralism. Studies in Science Education, 41, 91-116.

Zull, J. E. (2011). From Brain to mind: Using neuroscience to guide change in education. Sterling VA: Stylus Publishing 


\section{Tables}

Table 1 Descriptive information in each MSCLI scale

\begin{tabular}{|c|c|c|}
\hline Categories & Descriptions & Examples \\
\hline Emotions & $\begin{array}{l}\text { Students' emotions towards science } \\
\text { classes and the unit of acids and bases. }\end{array}$ & $\begin{array}{l}\text { I like the unit of acids and bases. } \\
\text { I am worried that I will not fully understand } \\
\text { the concepts of acids and bases. }\end{array}$ \\
\hline Intentions & $\begin{array}{l}\text { How intentions to gain affirmation } \\
\text { from others affect learning of physics } \\
\text { and chemistry }\end{array}$ & $\begin{array}{l}\text { I want my instructor to know that I am work- } \\
\text { ing hard on the unit of acids and bases. } \\
\text { I would work hard in science classes for the } \\
\text { praise from my parents. }\end{array}$ \\
\hline $\begin{array}{l}\text { Internal mental } \\
\text { representation }\end{array}$ & $\begin{array}{l}\text { Effects of image formation and trans- } \\
\text { forming of internal knowledge on } \\
\text { learning during the process of learn- } \\
\text { ing. }\end{array}$ & $\begin{array}{l}\text { When talking about the dissolving process of } \\
\text { electrolytes, my mental picture is that elec- } \\
\text { trolytes dissociate in water. } \\
\text { I can use pictures and graphics to demonstrate } \\
\text { the process of acid-base neutralization. }\end{array}$ \\
\hline $\begin{array}{l}\text { External mental } \\
\text { representation }\end{array}$ & $\begin{array}{l}\text { The utilization of representation of } \\
\text { acids and bases during problem solv- } \\
\text { ing }\end{array}$ & $\begin{array}{l}\text { Using the concepts of acid-base neutralization } \\
\text { and examples from daily life helps me solve } \\
\text { the problems of acids and bases. } \\
\text { A picture or graphic that comes with a prob- } \\
\text { lem about acid-base neutralization helps me } \\
\text { solve the problem. }\end{array}$ \\
\hline
\end{tabular}


Table 2 The concepts in the items of ABAT and the references of the concepts

\begin{tabular}{|c|c|c|c|}
\hline \multicolumn{2}{|c|}{ Item } & Concept & Reference \\
\hline \multicolumn{4}{|c|}{ Multiple-choice questions } \\
\hline$\bullet$ & $\begin{array}{l}\text { Which of the following is the collective char- } \\
\text { acteristic of acid materials? }\end{array}$ & $\begin{array}{l}\text { Macroscopic concept } \\
\text {-the characteristics of } \\
\text { acid }\end{array}$ & $\begin{array}{l}\text { Nakhleh \& Krajcik, } \\
\text { (1994) } \\
\text { Lin \& Chiu (2007) } \\
\text { Ouertatani et al. } \\
\text { (2007) } \\
\text { Boz (2010) }\end{array}$ \\
\hline$\bullet$ & $\begin{array}{l}\text { Which of the following is the collective char- } \\
\text { acteristic of base materials? }\end{array}$ & $\begin{array}{l}\text { Macroscopic concept } \\
\text {-the characteristics of } \\
\text { base }\end{array}$ & $\begin{array}{l}\text { Nakhleh \& Krajcik } \\
\text { (1994) } \\
\text { Lin \& Chiu (2007) } \\
\text { Ouertatani, et al. } \\
(2007) \\
\text { Boz (2010) }\end{array}$ \\
\hline$\bullet$ & Which of the following are not base materials? & $\begin{array}{l}\text { Macroscopic concept } \\
\text {-the identification of } \\
\text { base materials }\end{array}$ & $\begin{array}{l}\text { Nakhleh \& Krajcik } \\
\text { (1994) } \\
\text { Lin \& Chiu (2007) } \\
\text { Ouertatani et al. } \\
(2007) \\
\text { Boz (2010) }\end{array}$ \\
\hline$\bullet$ & $\begin{array}{l}\text { Which one of the following is the application } \\
\text { of neutralization in daily life? }\end{array}$ & $\begin{array}{l}\text { Macroscopic concept } \\
\text {-the judgments of } \\
\text { chemical reactions } \\
\text { about neutralization }\end{array}$ & $\begin{array}{l}\text { Lin \& Chiu (2007) } \\
\text { Ouertatani et al. } \\
(2007) \\
\text { Boz (2010) }\end{array}$ \\
\hline
\end{tabular}

- Dissolve 1 mole sulfuric acid in 10 liters of water, and then how many times the mole of hydrogen ion is counted to the mole of sulfate ion in this sulfuric acid aqueous?

- The following equation is about the ionization of calcium hydroxide aqueous:

$\mathrm{Ca}(\mathrm{OH})_{2} \rightarrow \mathrm{Ca}^{2+}+2 \mathrm{OH}^{-}$

What is the proportion of the numbers of $\mathrm{Ca}^{2+}$
Microscopic concept

Lin \& Chiu (2007) -the judgments of the ion numbers

Microscopic concept

Lin \& Chiu (2007) -the judgments of the ion numbers 
to $\mathrm{OH}^{-}$in $1 \mathrm{M}, 10$ liters calcium hydroxide

aqueous?

- What changes of the concentrations of $\left[\mathrm{H}^{+}\right]$and $\left[\mathrm{OH}^{-}\right]$in water when dissolved $1 \mathrm{~g}$ sodium hy-

Microscopic concept

-the changes of the

ion numbers

- Dissolve sodium hydroxide $(\mathrm{NaOH})$ in water, which statements of the following are correct?
Microscopic concept

-the changes of the

ion numbers
Furió-Más, et al.

(2005)

Furió-Más, et al.

\section{Drawing questions}

- Add quantitative chlorine calcium $\left(\mathrm{CaCl}_{2}\right)$ in Microscopic concept Lin \& Chiu (2007) the beaker of the following equipment. Try to draw the ionization and distribution situation. -the changes of the ion numbers
Furió-Más, et al.

(2005)

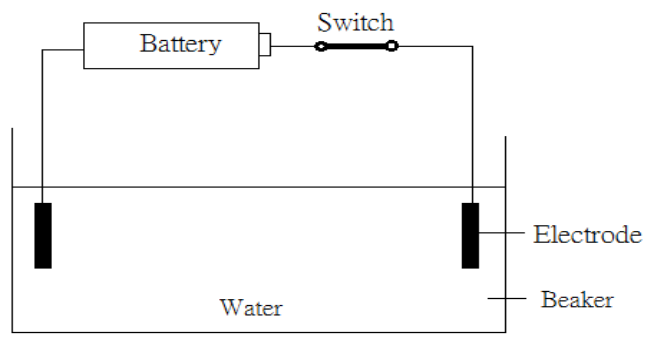

- Dilute $1 \mathrm{M} 10 \mathrm{~mL}$ sodium hydroxide aqueous into $100 \mathrm{~mL}$, and titrate by $0.5 \mathrm{M}$ diluted hydrochloric acid, then:

$\diamond \quad$ What situation do you think about the existence Microscopic concept Furió-Más, et al. of molecules and ions in beaker before titrat- $\quad$-the ion categories ing? and numbers

$\diamond \quad$ What situation about the existence of moleMicroscopic concept Furió-Más et al. cules and ions in beaker when adding $5 \mathrm{~mL}$ di-the ion categories (2005) luted hydrochloric acid in? and the changes of Ouertatani et al. ion numbers

$\diamond \quad$ What situation about the existence of moleMicroscopic concept Furió-Más, et al. cules and ions in beaker when the titration -the ion categories reaches to the end point? and the changes of ion numbers

Microscopic concept

Lin \& Chiu (2007) -the proportion calFurió-Más, et al. ric acid after titrating. culation of neutrali-

zation

Boz (2010) 
Table 3 Result of exploratory factor analysis

\begin{tabular}{|c|c|c|c|c|}
\hline \multirow{2}{*}{ Items } & \multicolumn{4}{|c|}{ Rotated Factors Pattern } \\
\hline & Emotions & Intentions & $\begin{array}{l}\text { Internal mental } \\
\text { representation }\end{array}$ & $\begin{array}{l}\text { External mental rep- } \\
\text { resentation }\end{array}$ \\
\hline 1 & .523 & & & \\
\hline 2 & .554 & & & \\
\hline 3 & .563 & & & \\
\hline 4 & .473 & & & \\
\hline 5 & .608 & & & \\
\hline 6 & .836 & & & \\
\hline 7 & 693 & & & \\
\hline 8 & .648 & & & \\
\hline 9 & .799 & & & \\
\hline 10 & .545 & & & \\
\hline 11 & & .555 & & \\
\hline 12 & & .747 & & \\
\hline 13 & & .811 & & \\
\hline 14 & & .795 & & \\
\hline 15 & & .807 & & \\
\hline 16 & & .507 & & \\
\hline 17 & & .658 & & \\
\hline 18 & & .439 & & \\
\hline 19 & & .403 & & \\
\hline 20 & & .414 & & \\
\hline 21 & & & 691 & \\
\hline 22 & & & .515 & \\
\hline 23 & & & .680 & \\
\hline 24 & & & .624 & \\
\hline 25 & & & .652 & \\
\hline 26 & & & .450 & \\
\hline 27 & & & .714 & \\
\hline 28 & & & .508 & \\
\hline 29 & & & .462 & \\
\hline 30 & & & .471 & \\
\hline 31 & & & & .473 \\
\hline 32 & & & & .561 \\
\hline 33 & & & & .459 \\
\hline
\end{tabular}


Table 4 Mean scores $(M)$, standard deviations(S.D.), internal consistency (Cronbach's $\alpha$ ), and discriminant validity (mean correlation with other scales) on MSCLI $(\mathrm{n}=267)$

\begin{tabular}{lccccc}
\hline Scale & Item & $M$ & $S . D$. & Cronbach's $\alpha$ & $\begin{array}{c}\text { Mean Correlation } \\
\text { with Other Scales }\end{array}$ \\
\hline Emotions & 10 & 3.36 & 0.74 & 0.88 & .39 \\
& 10 & 2.88 & 0.72 & 0.79 & .30 \\
Intentions & 10 & 2.66 & 0.62 & 0.71 & .48 \\
$\begin{array}{l}\text { Internal mental } \\
\text { representation }\end{array}$ & 10 & 3.87 & 0.65 & 0.70 & .40 \\
$\begin{array}{l}\text { External mental } \\
\text { representation }\end{array}$ & & & & & \\
\hline
\end{tabular}


Table 5 Descriptive analysis \& $F$-test value of MSCLI and ABAT before- and after-learning

\begin{tabular}{|c|c|c|c|c|c|}
\hline \multirow{3}{*}{ Group } & \multirow{3}{*}{$\mathrm{N}$} & \multicolumn{2}{|c|}{ Before-learning } & \multicolumn{2}{|c|}{ After-learning } \\
\hline & & ABAT & MSCLI & ABAT & MSCLI \\
\hline & & $M(S D)$ & $M(S D)$ & $M(S D)$ & $M(S D)$ \\
\hline High-achieving & 20 & $63.0(12.4)$ & $113.7(15.1)$ & $79.1(8.5)$ & $131.8(18.8)$ \\
\hline Middle-achieving & 27 & $49.7(16.5)$ & $112.2(20.3)$ & $57.6(6.6)$ & $119.0(14.0)$ \\
\hline Low-achieving & 21 & $34.7(18.6)$ & $102.9(16.0)$ & $31.6(8.6)$ & $112.7(13.5)$ \\
\hline$F$ & & $15.8 * * *$ & 2.38 & $189.2 * * *$ & $6.39 *$ \\
\hline
\end{tabular}

$* p<.05 ; * * * p<.001$

Table 6 Descriptive analysis of each of factors of MSCLI before and after learning

\begin{tabular}{|c|c|c|c|c|c|c|c|c|}
\hline & \multicolumn{4}{|c|}{ Before- learning } & \multicolumn{4}{|c|}{ After-learning } \\
\hline & Emotions & Intentions & IMR & EMR & Emotions & Intentions & IMR & EMR \\
\hline High- & 35.7 & 20.7 & 25.1 & 32.3 & 35.1 & 28.9 & 29.4 & 38.5 \\
\hline achieving & $(6.0)$ & (4.4) & (5.4) & (5.7) & $(7.5)$ & (4.9) & $(5.0)$ & (6.6) \\
\hline Middle- & 33.7 & 21.4 & 24.4 & 32.7 & 30.9 & 26.2 & 25.2 & 36.6 \\
\hline achieving & $(7.9)$ & $(6.4)$ & $(6.7)$ & (6.9) & $(9.4)$ & $(7.0)$ & $(6.2)$ & (6.0) \\
\hline Low- & 28.7 & 22.9 & 22.2 & 29.1 & 28.2 & 27.7 & 24.0 & 32.8 \\
\hline achieving & $(7.5)$ & $(6.6)$ & $(5.6)$ & $(6.6)$ & $(5.1)$ & $(5.7)$ & 4.8) & $(7.2)$ \\
\hline$F$ & $5.21 * *$ & .70 & 1.29 & 1.98 & $4.05^{*}$ & 1.15 & $5.47 * *$ & $4.07 *$ \\
\hline
\end{tabular}


Mental States in Learning Acid and Base Concept

(:) Please fill out your personal information.

Name :

Gender : ( )Male ( )Female

Grade : Class:

- If you are willing to give us more information, please write your phone number. We appreciate your help.

- Phone number:

\section{Guidelines}

1. This questionnaire will take around 20 minutes.

2. This questionnaire contains questions that situations dealing with acids and bases in chemistry class. We hope that this questionnaire will help your performance in chemistry class.

3. Your score from this questionnaire will have nothing to do with your grades in school.

4. There are no correct answers. We just want to know your opinion. What you write in this questionnaire will be confidential.

5. You will be asked about the regularity of certain situations. You may circle the answer you choose.

6. In the column under "Actual Situations," choose the answer that best relates to what has happened before in chemistry class. In the column under "Ideal situations," choose the answer that best presents what you hope to have happened in chemistry class.

7. Do you understand the explanations above?

( ) I fully understand.

( ) I still do not understand. 


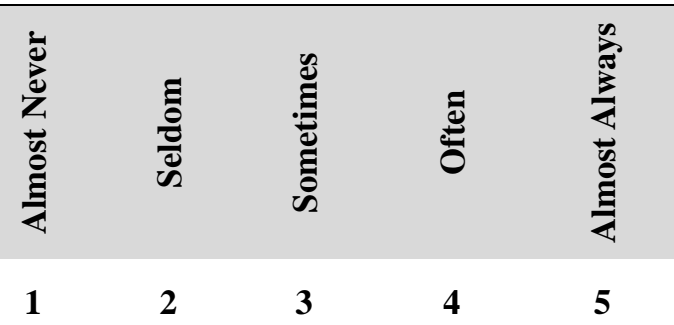

1.

$\begin{array}{lllllll}\text { I think having chemistry class is a fun thing to } & 1 & 2 & 3 & 4 & 5\end{array}$
do.

2.

$\begin{array}{llllll}\text {.I like chemistry class. } & \mathbf{1} & \mathbf{2} & \mathbf{3} & \mathbf{4} & \mathbf{5} \\ \text { I like the acids and bases unit. } & \mathbf{1} & \mathbf{2} & \mathbf{3} & \mathbf{4} & \mathbf{5}\end{array}$

3.

$\begin{array}{lllllll}\text { I find the unit on acids and bases interesting. } & 1 & 2 & 3 & 4\end{array}$

$\begin{array}{llllllll}\text { 5. I am in fear of the unit on acids and bases. } & \mathbf{1} & \mathbf{2} & \mathbf{3} & \mathbf{4} & \mathbf{5}\end{array}$

6. I think leaning about acids and bases makes $\quad \begin{array}{llllll}1 & 2 & 3 & 4 & 5\end{array}$ me miserable.

$\begin{array}{llllll}\text { 7. I worry about chemistry tests. } & \mathbf{1} & \mathbf{2} & \mathbf{3} & \mathbf{4} & \mathbf{5}\end{array}$

8.
I don't worry about the tests on acids and ba-
2
$\begin{array}{lll}3 & 4 & 5\end{array}$ ses.

9.

I am in fear of the tests on acids and bases.

10. I am worried that I will not fully understand

$\begin{array}{lllll}1 & 2 & 3 & 4 & 5\end{array}$

the concepts of acids and bases.

11.

$\begin{array}{lllllll}\text { I want my chemistry instructor to know that I } & 1 & 2 & 3 & 4 & 5\end{array}$

am working hard on the acids and bases unit.

12. I would work hard in chemistry class to im-

$\begin{array}{llllll}1 & 2 & 3 & 4 & 5\end{array}$

13. press other students.

$\begin{array}{lllllll}\text { I want to let my instructor know that I am } & & 1 & 2 & 3 & 4 & 5\end{array}$

good at the acids and bases unit.

14. I want to let my classmates know that I am

$\begin{array}{llllll}1 & 2 & 3 & 4 & 5\end{array}$

good at the acids and bases unit.

15.

I want to let other students know that I am

$1 \quad 2 \quad 3$

working hard on the acids and bases unit.

16.

I would work hard in chemistry class for

$\begin{array}{llllll}1 & 2 & 3 & 4 & 5\end{array}$

praise and rewards from my parents.

17.

I would work hard in chemistry class to make

12

23

4

5

my teacher like me. 


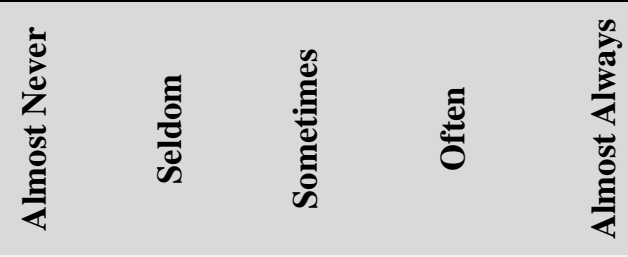

18.

I don't want to let others know that I can't

\section{1}

2

3

4

5

understand what the teacher teaching.

19.

In the presence of the instructor, I will pretend

1

2

3

4

5

that I fully understand everything.

20.

In the presence of other students, I will pre-

1

2

34

5

tend that I fully understand everything.

21.

When on the topic of the process of

$12 \quad 2 \quad 3$

4

5

acid-base neutralization, a picture of

molecules continuously reacting with

each other appears in my mind.

22. When on the topic of the process of acid-base neutralization, my mind pictures hydrogen atoms combining with hydroxide molecules to make hydrogen molecules that never dissociate afterwards.

23.

When on the topic of the process of

electrolyte, my mind pictures a situa-

1

2

3

4

5

tion in which electrolytes dissociate in

water.

24.

When on the topic of the process of 1 acid-base neutralization, my mind pictures hydrogen atoms and hydroxide molecules continuously associating and dissociating

25. I can explain the concepts of acids, ba-

1 ses, and salts to others.

26. I can use examples from daily life to
describe the phenomena of acid-base neutralization.

27. I use concepts related to acids, bases,

$\begin{array}{llllll}1 & 2 & 3 & 4 & 5\end{array}$

and acid-base neutralization in my daily

life. 


\begin{tabular}{|c|c|c|c|c|c|c|}
\hline & & 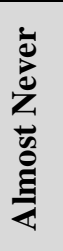 & है & 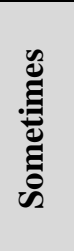 & $\stackrel{\Xi}{0}$ & 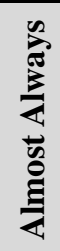 \\
\hline 28. & $\begin{array}{l}\text { I can use pictures and graphs to } \\
\text { demonstrate the process of acid-base } \\
\text { neutralization. }\end{array}$ & 1 & 2 & 3 & 4 & 5 \\
\hline 29. & $\begin{array}{l}\text { I doubt the accuracy of facts about acids and } \\
\text { bases that the instructor teaches. }\end{array}$ & 1 & 2 & 3 & 4 & 5 \\
\hline 30. & $\begin{array}{l}\text { I doubt the accuracy of the facts about acids } \\
\text { and bases in the textbook. }\end{array}$ & 1 & 2 & 3 & 4 & 5 \\
\hline 31. & $\begin{array}{l}\text { When solving problems, it is helpful } \\
\text { when I have reaction process related } \\
\text { information in my mind. }\end{array}$ & 1 & 2 & 3 & 4 & 5 \\
\hline 32. & $\begin{array}{l}\text { When solving problems, using the par- } \\
\text { allels between acid-base neutralization } \\
\text { and daily life examples help me figure } \\
\text { out the answer. }\end{array}$ & 1 & 2 & 3 & 4 & 5 \\
\hline 33. & $\begin{array}{l}\text { Using the teacher's similes and exam- } \\
\text { ples when solving problems is helpful. }\end{array}$ & 1 & 2 & 3 & 4 & 5 \\
\hline 34. & $\begin{array}{l}\text { A picture or graph that comes with a } \\
\text { problem dealing with acid-base neu- } \\
\text { tralization helps me solve the prob- } \\
\text { lem. }\end{array}$ & 1 & 2 & 3 & 4 & 5 \\
\hline 35. & $\begin{array}{l}\text { Reaction formulas given with a problem } \\
\text { dealing with acid-base neutralization } \\
\text { helps me solve the problem. }\end{array}$ & 1 & 2 & 3 & 4 & 5 \\
\hline 36. & $\begin{array}{l}\text { In acid-base neutralization, molecules } \\
\text { continue to associate and dissociate. }\end{array}$ & 1 & 2 & 3 & 4 & 5 \\
\hline 37. & $\begin{array}{l}\text { The collisions between molecules cause } \\
\text { continuous molecular motion. }\end{array}$ & 1 & 2 & 3 & 4 & 5 \\
\hline 38. & Household cleaning products are basic. & 1 & 2 & 3 & 4 & 5 \\
\hline 39. & Acids can be found in foods. & 1 & 2 & 3 & 4 & 5 \\
\hline 40. & $\begin{array}{l}\text { Reaction formulas show the atoms' } \\
\text { amounts, types, and products. }\end{array}$ & 1 & 2 & 3 & 4 & 5 \\
\hline
\end{tabular}

